\title{
Balancing Contractility and Energy Production: The Role of Myocyte Enhancer Factor 2 (MEF2) in Cardiac Hypertrophy
}

\author{
Michael P. Czubryt and ERic N. Olson \\ University of Texas Southwestern Medical Center at Dallas, Dallas, Texas 75390-9148
}

\begin{abstract}
Cardiac hypertrophy — that is, enlargement of the heart resulting from increased myocyte size — is observed with many forms of human heart disease. It may arise secondary to an insult, such as infarct or chronic hypertension, or may occur as a consequence of a genetic defect, such as in hypertrophic cardiomyopathy. Traditionally, it has been widely believed that hypertrophy occurred as an adaptive response to normalize increased wall stress due to disease. Recently, however, it has been observed that while hypertrophy initially appears to improve the function of the heart following insult, over time, it frequently leads to a decompensated state, characterized by fibrosis and chamber dilation, resulting in overt heart failure. Hypertrophy also occurs during fetal development, immediately after birth, and in trained athletes; however, it does not lead to decompensation in these states. Experiments over the last 15 years have implicated similar signaling pathways in both pathological and physiological hypertrophic responses. Recently, important differences have been demonstrated that might hold the key to the development of effective new treatments for human diseases. This chapter focuses on how these hypertrophic responses differ from one another phenotypically and discusses how inefficient or impaired energy metabolism in the heart may contribute to the development of pathological responses. We also discuss recent evidence that the myocyte enhancer factor 2 (MEF2) transcription factor family, which previously has been shown to be important in cardiac development and hypertrophy, may have a role in regulation of cardiac energy metabolism.
\end{abstract}

\section{Cardiac Hypertrophy}

The term "cardiac hypertrophy" refers to enlargement of the heart due primarily to an increase in the size of individual cardiomyocytes. The term often is used to refer to a pathological response to an experimental insult or to the introduction of a transgene. However, it is important to differentiate pathological hypertrophy from physiological hypertrophy, in which cardiac enlargement occurs without significant clinical consequences. It is also important to differentiate between early stages of pathological hypertrophy, during which changes in cardiac structure compensate for increased stress on the heart, and later stages, when the heart becomes decompensated, resulting in cardiac failure and increased morbidity and mortality. 


\section{A. PHYSIOLOGICAL HYPERTROPHY}

After birth, the heart continues to grow for a limited period to adapt to increased workload. In particular, the left side of the heart undergoes hypertrophy, while the right side actually gets slightly smaller due to changes in blood pressure throughout the heart that occur soon after birth. The first few breaths after birth fill the lungs with air, decreasing afterload on the right side of the heart and increasing pulmonary vascular blood flow. This increases blood flow to the left side of the heart, increasing preload. Mean arterial blood pressure rises throughout the newborn's body and increases the mechanical afterload on the heart. It is the increased workload on the heart, specifically on the left side, that leads to increased heart size. The changes in cardiac size after birth result from both hypertrophy and hyperplasia of cardiomyocytes but as cardiomyocytes terminally differentiate during the first few weeks of life, further increases in heart size throughout life are due primarily to hypertrophy (Oparil et al., 1984).

Cardiac hypertrophy also occurs following (typically long-term) exercise training. The heart increases in size and mass following resistance training such as weight lifting, although there is some debate as to whether true hypertrophy occurs in this scenario. Normalizing the increased heart weight to the increased body weight of the athletes appears to greatly reduce the increased ratio typically observed in true hypertrophy (Oakley, 2001; Haykowsky et al., 2002). Nevertheless, resistance athletes frequently demonstrate some degree of concentric hypertrophy (increased wall thickness with normal chamber dimensions). In the case of isotonic training (e.g., distance running), cardiac hypertrophy is much more obvious and often presents as an eccentric hypertrophy (increased wall thickness with increased chamber dilation) (Oakley, 2001).

Hypertrophy in athletes is frequently of sufficient degree to cause alterations in electrocardiograms, although these changes do not seem to correlate with increased susceptibility to disease (Oakley, 2001). Indeed, cardiac hypertrophy in athletes appears to be beneficial, since stroke volume is increased at the same time that resting heart rate is decreased, resulting in more-efficient pumping of blood (Scharhag et al., 2002). Despite news media reports of college or professional athletes dropping dead of heart attacks or arrhythmias during practice, sudden cardiac death is extremely rare among elite athletes and occurs less frequently than in the general population (Futterman and Myerburg, 1998). Recent studies have concluded that the vast majority of cases of sudden death in athletes occur as a result of previously undiagnosed genetic predisposition or defect that becomes exacerbated during exercise (Futterman and Myerburg, 1998; Basso et al., 1999). Furthermore, the typical sequelae of pathologic hypertrophy (i.e., increased fibrosis and cardiac decompensation) usually do not follow physiological cardiac hypertrophic growth, indicating that this form of hypertrophy is truly beneficial to the individual. 


\section{B. PATHOLOGICAL HYPERTROPHY}

Pathological forms of cardiac hypertrophy frequently occur following acute events, such as myocardial infarction, or accompanying chronic insults such as hypertension. In these examples, hypertrophy is thought to be an attempt to relieve increased transmural wall stress in the heart by thickening the wall, thereby exploiting the law of Laplace (Morisco et al., 2003). Various inherited genetic disorders also result in cardiac hypertrophy as either a primary or secondary endpoint. For example, hypertrophic cardiomyopathy is an inherited disease that can result from a wide variety of genetic lesions, including mutations in contractile proteins such as $\beta$-myosin heavy chain that may directly result in cardiac hypertrophy (Arad et al., 2002). Alternatively, hypertrophy may represent a secondary response to a distal lesion, such as occurs in pheochromocytoma, a tumor that uncontrollably releases epinephrine and norepinephrine to continually activate adrenergic pathways in the heart (Prichard et al., 1991). Pathologic hypertrophy thus typically represents an attempt by the heart to alleviate a stress or a response to inappropriate alteration of prohypertrophic signaling pathways.

Pathologic hypertrophy essentially can be divided into two subcategories, representing two different stages of the pathologic process.

\section{Compensation}

The early stage of pathologic cardiac hypertrophy is termed "compensation" because, in response to a stress, the heart walls thicken in an attempt to compensate for the increased stress. This enlargement is due to increased cardiomyocyte size as well as to increased deposition of collagens and other extracellular matrix components in a process called fibrosis, which may account for a significant proportion of the size increase. By increasing cardiac wall volume, fibrosis helps alleviate transmural stress. However, stiffness of the cardiac muscle increases and compliance decreases as fibrosis progresses (Jalil et al., 1989). Over time, fibrosis actually can impair normal cardiac function (see following section on decompensation). Since fibrosis does not typically occur during physiologic hypertrophy, it is a logical therapeutic target, especially since significant fibrosis is usually a harbinger of a shift to decompensation.

A classic example of compensation occurs in response to hypertension. Increased afterload due to increased mean arterial pressure activates stretch receptors in cardiomyocytes. For example, $\beta$-integrin in the sarcolemmal membrane is coupled via its cytoplasmic tail to a complex of proteins in the Z-disc, including $\alpha$-actinin and talin (Sadoshima and Izumo, 1997). Through a process that is not yet completely understood, cell stretching stimulates this complex and leads to activation of downstream signaling pathways, including the Ras/mitogen-activated protein kinase (MAPK) and phosphatidylinositol 3-kinase/AKT/ 
glycogen synthase kinase (PI-3K/AKT/GSK3)- $\beta$ /calcineurin cascades (Sadoshima and Izumo, 1997). Activation of components of both of these pathways has been linked to cardiac hypertrophy in experimental animals. For example, transgenic mice overexpressing activated forms of the MAPKs mitogen extracellular signal-regulated kinase (MEK)1 and MEK5 present with concentric and eccentric hypertrophy, respectively (Bueno et al., 2000; Nicol et al., 2001). Interestingly, however, mice overexpressing MEK1 appear to model a physiological form of hypertrophy, with no signs of disease at 12 months of age, despite hypertrophy, whereas MEK5-overexpressing mice quickly proceed to failure. Overexpression of a constitutively active form of calcineurin also leads to dramatic hypertrophy, eventually leading to decompensation and failure (Molkentin et al., 1998). Conversely, overexpression of constitutively active GSK-3 $\beta$, which counteracts the actions of calcineurin by phosphorylating and inactivating downstream targets of calcineurin (the nuclear factor of activated T cell (NFAT) transcription factors), blunts the hypertrophic response to a variety of stimuli, including systemic isoproterenol administration and aortic banding (Antos et al., 2002).

Many other factors and pathways are involved in activation of the hypertrophic program in the heart, including neurohumoral factors (e.g., angiotensin II, adrenergic stimulation) and paracrine influences and interactions between cardiomyocytes and other cell types found in the heart (e.g., fibroblasts, endothelial and vascular smooth muscle cells). Comprehensive coverage of these pathways, however, is beyond the scope of this review. The reader is directed to several recent reviews (Sadoshima and Izumo, 1997; Frey and Olson, 2003).

\section{Decompensation}

Compensated cardiac hypertrophy frequently devolves into the latter stage of hypertrophy, decompensation. As mentioned earlier, significant cardiac fibrosis typically precedes decompensation and likely plays a causative role. As collagen fibrils are deposited in the cardiac interstitium, cardiac function becomes progressively impaired. Eventually, the heart is unable to pump enough blood to meet the body's demands and patients go into overt cardiac failure. Although various treatments are available to heart failure patients that attempt to preserve cardiac function, mortality remains high.

Although fibrosis can reduce stroke volume and ejection fraction, the ramifications may be more serious for diastolic, rather than systolic, function. Many heart failure patients actually have preserved systolic function but increased wall stiffness due to fibrosis results in reduced diastolic filling, with the net result that less blood is available to be pumped to the body during each beat (Kitzman, 2000). Nonetheless, it is clear that increased fibrosis is a significant problem in patients with cardiac hypertrophy. Several factors have been identi- 
fied that can stimulate fibrosis in animal models, such as transforming growth factor-beta1 (TGF- $\beta 1$ ); however, the signaling cascade(s) leading to fibrosis remain unclear (Kuwahara et al., 2002). Fibrosis does not typically occur during exercise-induced hypertrophy. At the same time, many of the same hypertrophic signaling pathways appear to be involved in both physiological and pathological responses. For example, recent studies with transgenic mice expressing inhibitors of calcineurin showed attenuation of cardiac hypertrophy in response to not only exercise but also to aortic banding (pressure overload model), isoproterenol ( $\beta$-adrenergic activation), and transgenic calcineurin overexpression (De Windt et al., 2001; Rothermel et al., 2001). Together, these data indicate a role for calcineurin in both physiological and pathological cardiac hypertrophy. Since similar genetic pathways may be activated in both forms of hypertrophy, examining how the metabolism of the exercised heart contrasts with that of the failing heart may shed light on the phenomena of fibrosis and hypertrophy in general and lead to improved therapies.

\section{Energy Metabolism in Hypertrophy}

In contrast to most other tissues that rely on glucose oxidation for energy, cardiomyocytes depend primarily on the mitochondrial oxidation of fatty acids for fuel, deriving up to $60 \%$ or more of the cell's energy budget from this source (van der Vusse et al., 2000). Fatty acids are a richer energy source than glucose: complete oxidation of a six-carbon fatty acid yields 44 molecules of adenosine triphosphate (ATP), compared to 38 from glucose oxidation. However, fatty acid oxidation is completely dependent on oxygen, which is critically important in the context of the extremely high ATP demands of the cardiomyocyte, while glucose oxidation has a lower oxygen requirement. During short-term exertion or ischemia, when oxygen supply may be severely limited, glycolysis can become more important than oxidation for meeting the cell's energy requirements. However, anaerobic glycolysis provides only two molecules of ATP per glucose molecule, since glucose is metabolized to lactate instead of to acetyl-CoA, which enters the Krebs cycle and drives oxidative phosphorylation (Carvajal and MorenoSanchez, 2003). A switch to glucose as a preferred substrate, with a concomitant reduction in fatty acid oxidation, also occurs during cardiac hypertrophy and failure (see below). The heart can metabolize a variety of other energy sources (e.g., ketone bodies, lactate), when present in sufficient quantities. The contribution of various energy-producing pathways to net ATP synthesis can be affected by various metabolites and intermediaries found in cardiomyocytes, including malonyl-CoA and L-carnitine (Carvajal and Moreno-Sanchez, 2003). The energy-producing machinery of the heart thus is highly tuned to meet the specific and significant demands of individual myocytes. Stresses acting on these 
processes that may affect the efficiency of energy production may, therefore, have serious consequences for the heart as a whole.

It is difficult to determine whether changes in myocardial metabolism necessarily precede pathologic hypertrophy or simply whether metabolic changes occur only after the hypertrophic cascade has begun. The reality is likely that both scenarios occur to some degree in human disease: metabolic changes may occur as a result of insult or genetic defect/predisposition, leading to hypertrophy, which, in turn, imposes its own metabolic consequences on cardiomyocyte function and exacerbates the situation. The specific genotype of the individual would be expected to influence not only whether pathologic hypertrophy occurs in response to a particular stress but also how quickly the disease progresses and in what form it manifests (e.g., concentric vs. eccentric hypertrophy, left-sided vs. right-sided failure). The interplay between genotype and phenotype is highly complex, with each side of the equation influencing the other. Therefore, it may be unlikely that a one-size-fits-all therapy will be found, although continued basic research will highlight promising avenues, while revealing dead ends.

It is certainly true that defects in metabolism can result in hypertrophy and related cardiomyopathies such as dilated cardiomyopathy, in which cardiac chambers become dilated and the ventricular walls thinned, resembling decompensation and resulting in heart failure. Many cardiac diseases result from primary or secondary mitochondrial defects. For example, both dilated and hypertrophic cardiomyopathy have been associated with point mutations in mitochondrial DNA coding for tRNAs and metabolic genes such as cytochrome $\mathrm{b}$ and cytochrome c oxidase (Marin-Garcia and Goldenthal, 2002; Antonicka et al., 2003). Release of cytochrome c from mitochondria activates caspase-9mediated apoptosis (Green and Reed, 1998). Increased cardiomyocyte apoptosis can cause dilated cardiomyopathy and heart failure (Wencker et al., 2003; Yamamoto et al., 2003). In some instances, defects in mitochondria are secondary to other phenomena, yet still evoke cardiac hypertrophy. Recently, it was shown that deletion of the intermediate filament protein desmin results in extensive derangement of mitochondria in cardiac and skeletal muscles of desmin-null mice (Milner et al., 2000). This loss precedes development of cardiac hypertrophy, which eventually devolves into ventricular dilation and cardiac failure (Milner et al., 1999). It would appear, then, that alteration of normal mitochondrial structure and/or function may lead to hypertrophy and cardiac failure.

Conversely, recent studies indicate that energy metabolism in the heart changes during pathologic hypertrophy. It has been well documented that during cardiac hypertrophy and failure, the contribution to energy production by glycolysis is augmented significantly (Allard et al., 1994; Leong et al., 2002). At the same time, energy production by fatty acid oxidation significantly decreases as glucose becomes the favored fuel (Allard et al., 1994; Sack et al., 1996). This 
shift may represent an adaptive response whose purpose is to preserve cardiac function under increased demands, since glucose oxidation requires less oxygen consumption than fatty acid oxidation. Evidence for this comes from reports that heart failure patients given medications that inhibit fatty acid oxidation and favor glucose oxidation have improved prognoses with reduced mortality (Eichhorn et al., 1994; Wallhaus et al., 2001).

The mechanism by which this switch in substrate utilization occurs may involve regulation of transcription and mobilization of the major glucose transporters in the heart, GLUT1 and GLUT4. GLUT1 is responsible for basal glucose import into cardiomyocytes, while GLUT4, although present at higher levels than GLUT1, is responsible for insulin-mediated glucose import (Young et al., 1999). In response to increased energy demand by the heart - for example, during ischemia - there is increased recruitment of both transporters to the sarcolemmal membrane, although the response is greater for GLUT4 (Young et al., 1997). Results in skeletal muscle also suggest that expression of GLUT4 may increase with exercise (Langfort et al., 2003). In cardiac hypertrophy, GLUT1 levels rise, while GLUT4 expression is reduced, which may account for the insulinindependent increase in glucose uptake noted in hypertrophy (Montessuit and Thorburn, 1999; Liao et al., 2002). In overt cardiac failure, however, GLUT1 levels decrease, suggesting the possibility that the transition from compensated to decompensated hypertrophy may involve significant loss of ATP-generating capability by glucose oxidation (Razeghi et al., 2002). This concept is supported by the report that cardiac-specific overexpression of GLUT1 was able to prevent conversion of hypertrophy to heart failure by preserving glucose import and glycolysis following ascending aortic constriction (Liao et al., 2002). It is also intriguing that cardiac-specific deletion of GLUT4 in mice results in cardiac hypertrophy but with preserved contractile function and no fibrosis, similar to compensated hypertrophy (Abel et al., 1999). This deletion may mimic the natural decrease in GLUT4 expression that accompanies hypertrophy and suggests that a decrease in energy production capability may precede disease (Liao et al., 2002).

Ultimately, it may be loss of energy stores, either due to decreased synthesis or increased consumption of high-energy compounds like ATP, which may be the critical factor in the shift from compensated to decompensated hypertrophy. Jung and Dietze reported in a survey of ${ }^{31} \mathrm{P}$ nuclear magnetic resonance (NMR) studies in humans that the phosphocreatine/ATP ratio, a measure of energy stores in the heart, was reduced in patients with aortic stenosis or mitral regurgitation (Jung and Dietze, 1999). In contrast, the hearts of elite cyclists showed no change in this ratio, suggesting that fundamental differences exist between cardiac metabolism in physiological and pathological hypertrophy. Recent studies in a pig model of myocardial infarction to produce cardiac remodeling and failure also demonstrate loss of energy stores, with the loss proportional to the severity 
of the disease (Liu et al., 2001; Ye et al., 2001). Another recent study has identified myocardial fatty acid metabolism as an independent predictor of left ventricular mass in heart disease arising as a consequence of hypertension, although it is unclear whether changes in fatty acid metabolism also predict cardiovascular morbidity and mortality (de las Fuentes et al., 2003). Together, these findings reveal that energy metabolism changes significantly in the hypertrophied heart but also suggest that the changes that occur during physiological vs. pathological hypertrophy are different. A recent paper has advanced an intriguing hypothesis of inefficient ATP utilization underlying hypertrophic cardiomyopathy and provides an interesting model for how both contractile and noncontractile protein mutations can lead to ATP loss (Ashrafian et al., 2003). These cited studies suggest that defects in ATP generation or usage, resulting in decreased energy stores, actually may underlie pathologic hypertrophic scenarios in general, regardless of the exact cause. Potential regulatory pathways involved in this process will be discussed later. Unfortunately, while significant resources have been devoted to analyzing pathologic changes in the heart, much less work has been done to identify metabolic changes occurring during physiological hypertrophy. Because it is not clear exactly how these two phenotypes differ, further research is needed in this area.

Another issue requiring further examination is the mechanism by which changes in metabolism can lead to hypertrophy. One argument suggests that altered metabolism results in less-efficient production of ATP by the various bioenergetic pathways in the heart. The net result is that more fuel is required to produce each mole of ATP and thus more fuel is required to do a given amount of work. If fuel is limiting, work output consequently will decrease. Since the definition of heart failure is "the inability of the heart to pump sufficient blood to meet the body's needs," if inefficiency is high enough, work output can decrease enough to put the heart into failure. Any added stresses, such as increased afterload due to hypertension or valve stenosis, or genetic defects that reduce work output (e.g., contractile protein defects) would exacerbate the consequences of the underlying inefficiency.

Indirect evidence to support this hypothesis has been found in studies of the adenosine monophosphate-activated protein kinase (AMPK). AMPK is activated in response to an elevation in the ratio of AMP:ATP. As muscle shifts from a sedentary to active state, increased metabolism will raise the turnover rate of ATP, resulting in an increased pool of AMP and a decrease in ATP levels, thereby activating AMPK. AMPK activation increases the activity of numerous downstream pathways involved in energy production. Therefore, AMPK behaves as a bioenergetic sensor and feedback apparatus, becoming activated when energy stores are low and, in turn, activating energy replenishment programs, including fatty acid oxidation and glycolysis (Hopkins et al., 2003). As one would expect, AMPK becomes activated in the heart during exercise, with the 
degree of activation proportional to the degree of work performed (Coven et al., 2003). However, it also has been reported that AMPK is activated during pressure-overload hypertrophy (Tian et al., 2001). This activation suggests that energy stores were being depleted in the hypertrophied heart, in agreement with the report noted earlier in which ${ }^{31} \mathrm{P}$ NMR revealed energy depletion (Jung and Dietze, 1999). It must be noted that, at this time, it is unclear whether inefficiency of ATP synthesis or work performance, or even some other cause, is behind the energy depletion observed in pressure-overload hypertrophy.

Another possibility for how altered energy metabolism leads to cardiac hypertrophy involves generation of reactive oxygen species (ROS), such as superoxide and hydroxyl radicals, and hydrogen peroxide. Exactly how ROS cause hypertrophy is unclear but numerous studies have implicated ROS production in the hypertrophic process. During the progression of hypertrophy to failure in a guinea pig model, nicotinamide adenine dinucleotide phosphate (NADPH) oxidase, an important source of ROS, is activated, with increased expression of various subunits of the enzyme and increased production of superoxide radicals, a ROS that can lead to production of more-toxic species ( $\mathrm{Li}$ et al., 2002). Recently, it was shown that the transgenic calcineurin mouse model of hypertrophy produces increased levels of superoxide (Sayen et al., 2003). Electron spin trap experiments have demonstrated increased generation of hydroxyl radicals arising from superoxide radicals and hydrogen peroxide in failing canine hearts (Ide et al., 2000). Furthermore, the degree of cardiac dysfunction correlated positively with levels of ROS generation.

ROS may arise from numerous sources within cardiomyocytes as well as within other cell types found in the heart. Normal oxidative metabolism produces ROS due to leakage out of the electron transport chain. Numerous antioxidant systems exist within the cell to prevent damage (Czubryt et al., 1996). If ROS synthesis becomes highly elevated or antioxidant levels reduced, ROS may become toxic by interacting with and inactivating or destroying almost any molecule in the cell. However, it is unclear what sources may produce sufficient quantities of ROS to affect cardiac metabolism in otherwise-healthy tissue. One theory suggests that some ROS are generated during normal fatty acid oxidation, when some metabolites are only partially oxidized to form radical species. As fatty acid oxidation increases to meet increased workload, ROS are generated in greater numbers. If the workload elevation is chronic, over time, the antioxidant defenses of the cell are neutralized and ROS builds to toxic levels. Another possibility is that increased workload over time may increase necrosis of cardiomyocytes. As cells die, monocytes and macrophages move into the myocardium, both of which produce high levels of ROS during respiratory bursts (Czubryt et al., 1996). The exact site of ROS production may be unimportant, since some species (e.g., hydrogen peroxide) freely cross cell membranes, allowing migration of ROS into cardiomyocytes and resulting in damage. 
Finally, it has been reported that inhibition of oxidative phosphorylation in Ant ${ }^{\text {tm2Mgr }}(-/-)$ knockout mice results in increased production of hydrogen peroxide, which can contribute to the formation of more-toxic ROS (Esposito et al., 1999). This is especially important when considering the inhibition of oxidative phosphorylation that occurs when oxygen is limited, such as during ischemia. This may be highly relevant in some forms of hypertrophy such as idiopathic dilated cardiomyopathy, where tissue perfusion and oxygen delivery can be reduced in the cardiac wall (van den Heuvel et al., 2000).

\section{Myocyte Enhancer Factor 2 (MEF2), Hypertrophy, and Energy Metabolism}

Our laboratory has focused on genetic signaling pathways involved in the process of cardiac hypertrophy. Of particular interest has been the MEF2 family of transcription factors, which consists of four members (A, B, C, and D) (Black and Olson, 1998). MEF2 transactivates expression of numerous hypertrophic marker genes. MEF2 activity measured in a transgenic mouse expressing a MEF2-responsive reporter is increased during hypertrophy due to overexpression of activated calmodulin-dependent protein kinase IV (CaMKIV) (Passier et al., 2000). MEF2 activity is attenuated by the class II histone deacetylases (HDACs), which bind specifically to MEF2 and block transactivation (Lu et al., 2000a,b; McKinsey et al., 2000a,b). The class II HDACs include HDAC4, -5, -7, and -9. This repression is relieved by phosphorylation of HDACs by calcium/CaMK and other kinases, which phosphorylate HDACs on two conserved serine residues. This phosphorylation inhibits HDAC binding to MEF2 and creates a target binding site for the chaperone protein 14-3-3, which then binds to the HDAC and escorts it out of the nucleus (McKinsey et al., 2000b). This mechanism may explain, at least in part, the hypertrophy observed in CaMKIV-overexpressing mice. Release of HDACs is accompanied by association of the histone acetyltransferase p300 with MEF2 and consequent activation of MEF2 target genes (Eckner et al., 1996; Sartorelli et al., 1997; Slepak et al., 2001).

Since MEF2 appears to play a role in the hypertrophic response, and since class II HDACs repress MEF2 activity, we sought to determine whether a mutant HDAC that constitutively binds MEF2 could repress the hypertrophic program. We used human HDAC5 in which serines 259 and 498 were mutated to alanines (HDAC5-S259/498A) to prevent phosphorylation. This construct successfully blocked the hypertrophic response of cardiomyocytes to prohypertrophic agents such as phenylephrine (Zhang et al., 2002). However, initial attempts to create transgenic mice expressing this construct in the heart were unsuccessful, since only mosaic animals were obtained at birth that did not transmit the transgene to their offspring, leading us to suspect that the transgene may be lethal in the embryo. We therefore incorporated a tet-off system to allow heart-specific 
conditional induction of the transgene in mice. In the presence of the tetracycline analog doxycycline, the transgene is silent but becomes fully activated within a few days after withdrawal of the drug (Yu et al., 1996). Besides blocking hypertrophy, it was hoped that gene expression changes in these animals might indicate the existence of as-yet-unidentified MEF2 target genes.

Although several markers of hypertrophy appear to be downregulated initially, several days after transgene induction, these markers (including atrial natriuretic factor (ANF), brain natriuretic peptide (BNP), and cardiac ankyrin repeat protein (CARP)) become highly upregulated. This is possibly due to induction of a hypertrophic signaling cascade that is independent of MEF2. In fact, female transgenic mice develop a dilated cardiomyopathy resembling end-stage heart failure within 30 days of transgene activation, characterized by chamber dilation and ventricular wall thinning (M. Czubryt and E. Olson, unpublished data). However, the model was particularly interesting because male mice, in contrast to the females, died within 8 to 10 days after withdrawal of doxycycline, exhibiting signs of acute heart failure, including bradycardia and lethargy. Examination of the hearts of male mice revealed myocyte loss and damaged mitochondria in the remaining cells, although there was no change in cardiac mass (Czubryt et al., 2003). A gene chip analysis of these animals revealed significant downregulation of numerous enzymes involved in fatty acid oxidation, including the transcriptional coactivator peroxisome proliferator-activated receptor (PPAR) gamma coactivator- $1 \alpha$ (PGC- $1 \alpha)$.

PGC- $1 \alpha$ coactivates the PPAR class of transcription factors, which are related to the nuclear hormone receptor superfamily (Lehman and Kelly, 2002). PPAR $\gamma$ regulates the expression of several key enzymes involved in fatty acid oxidation. The expression of at least two of these enzymes is coactivated by PGC-1 $\alpha$ (Vega et al., 2000). Our mice expressing the HDAC5 mutant transgene showed a dramatic downregulation of PGC- $1 \alpha$ expression, as well as the two known coactivated targets of PGC- $1 \alpha$, and several other enzymes that may, in fact, be additional targets of PGC-1 $\alpha$ (Czubryt et al., 2003). Expression of PPAR $\gamma$ itself was not affected in these animals.

Examination of the PGC- $1 \alpha$ promoter revealed the existence of two putative MEF2 binding sites, which we confirmed did, in fact, bind MEF2 specifically and conferred MEF2 and HDAC5 regulation to a luciferase reporter under control of the PGC-1 $\alpha$ promoter (Czubryt et al., 2003). Chromatin immunoprecipitation analysis revealed significant deacetylation of the more distal of the two MEF2 sites, in response to transfection of neonatal cardiomyocytes with an adenovirus expressing the HDAC5 mutant. It therefore appears that PGC- $1 \alpha$ is a bona fide target of MEF2 and HDAC signaling. A recent study by Handschin et al. (2003) suggests that calcineurin may play a role in regulation of PGC- $1 \alpha$ expression and reports that PGC- $1 \alpha$ itself is required for activation of the PGC- $1 \alpha$ promoter by MEF2. In contrast to our findings, this report did not observe activation of the 
promoter by MEF2 alone. However, this may be due to differences in the cell types chosen for reporter assays, since the cultured muscle cells used in this study may be deficient in endogenous PGC- $1 \alpha$ (Michael et al., 2001). This discrepancy also may be due to the fact that our study used a $3-\mathrm{kb}$ promoter fragment containing two MEF2 sites, compared to the $2-\mathrm{kb}$ promoter fragment used in Handschin's study that contained only one MEF2 binding site, which may alter sensitivity of the promoter to MEF2 activation.

Our results suggest that MEF2 may play a much-wider role in cardiac metabolism than previously suspected, including regulation of fatty acid oxidation in the heart and maintenance of mitochondrial function. In support of this hypothesis, our laboratory recently reported that deletion of MEF2A in mice results in derangement of mitochondrial structure, significant loss of mitochondria accompanied by reduced cytochrome c oxidase activity, cardiac dilation, and activation of a fetal gene program reminiscent of that activated in heart failure (Naya et al., 2002). A recent report suggests that PGC- $1 \alpha$ may have a wider role to play than initially believed, since PGC- $1 \alpha$ coactivated the expression of several MEF2 target genes involved in oxidative slow fiber formation in skeletal muscle (Lin et al., 2002). One of the MEF2 targets coactivated in this study, myoglobin, may be considered a bioenergetic protein but the other target, troponin I slow, regulates contractile activity. In light of the variety of genes regulated by MEF2 that are coactivated by PGC- $1 \alpha$, it is intriguing to consider the possibility that PGC- $1 \alpha$ and MEF2, together, may be involved in the regulation of both bioenergetic and hypertrophic contractile genes under MEF2 transactivational control.

When the heart undergoes a sustained increase in workload, many changes occur in the milieu of the cardiomyocyte, including ATP depletion and increased calcium levels (Fralix et al., 1991). In light of a potential role for MEF2 in regulating expression not only of contractile proteins but also fatty acid oxidation enzymes, a model can be envisioned in which MEF2 and PGC- $1 \alpha$ coordinately regulate the heart's response to increased workload (Figure 1). The decrease in ATP levels and rise in intracellular calcium concentration activates the two major pathways of this model by activating AMPK and CaMK, respectively. Activation of these pathways eventually results in stimulation of MEF2 transactivation and increased synthesis of PGC- $1 \alpha$. By regulating contractile protein and metabolic enzyme gene transcription with the same transcription factor, both the capability to do more work by increasing myofiber number and the capability to supply the energy necessary to perform that work can be up- and downregulated proportionally to one another. An accumulating body of evidence supports many aspects of this model.

With sustained work, the AMP:ATP ratio increases, as energy supplies are exhausted faster than they can be replenished, eventually triggering energygeneration programs through activation of AMPK. Recently, it has been shown 


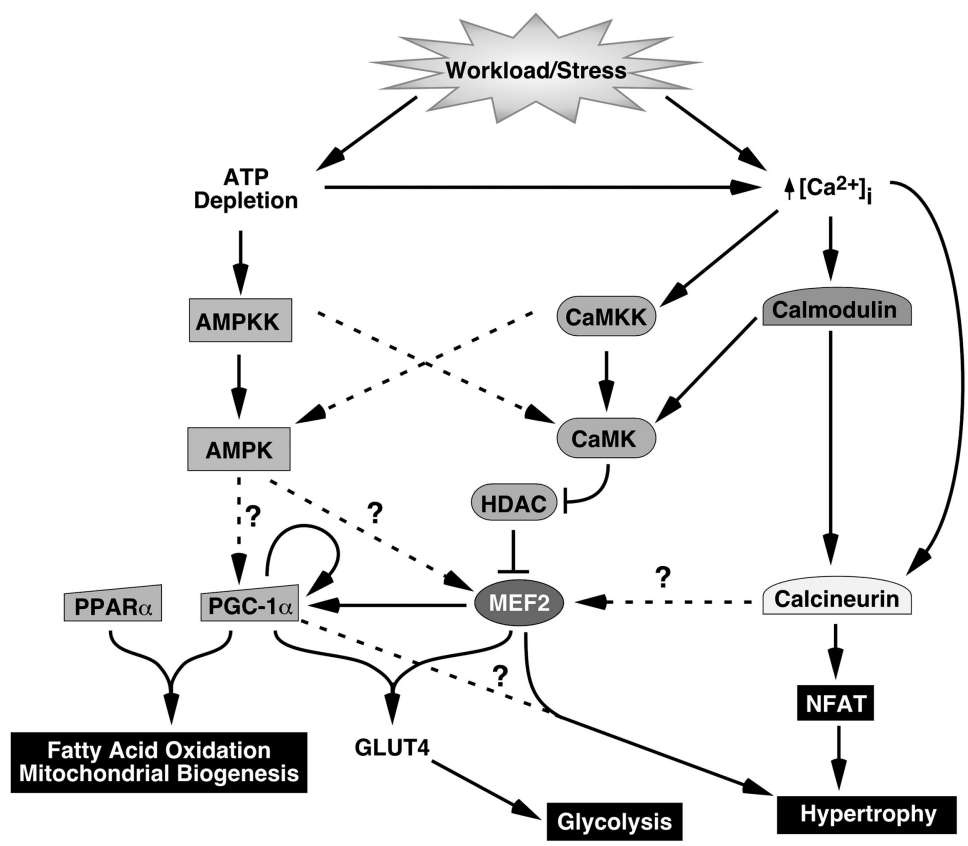

FIG. 1. Myocyte enhancer factor 2 (MEF2) participates in transducing adenosine triphosphate (ATP) and calcium signals to mediate hypertrophic gene expression. In response to increased workload or stress (e.g., inefficient coupling of excitation and contraction, inefficient contraction due to genetic defect), ATP levels fall and intracellular calcium concentration rises. The rise in intracellular calcium may be exacerbated when ATP levels are low due to reduced activity of calcium pumps in the sarcolemma or sarcoplasmic reticulum, resulting in reduced calcium sequestration during relaxation. Increased adenosine monophosphate (AMP):ATP ratio activates AMP-activated protein kinase (AMPK) kinase, or AMPK directly, while at the same time, increased calcium concentration activates calcium/calmodulin-dependent protein kinase (CaMK) kinase and calmodulin, which, in turn, activate CaM kinases. Activated CaMKs activate MEF2-regulated transcription by phosphorylating histone deacetylases (HDACs), which repress MEF2 transactivation, resulting in HDAC release from MEF2 and export of HDACs from the nucleus by 14-3-3. Activated AMPK increases transcription of peroxisome proliferator-activated receptor (PPAR) gamma coactivator- $1 \alpha$ (PGC-1 $\alpha$ ) and MEF2A and MEF2D via an unknown mechanism. PGC- $1 \alpha$ also coactivates its own expression, ostensibly mediated by MEF2. PGC- $1 \alpha$ and PPAR $\gamma$ cooperate to drive expression of fatty acid oxidation enzymes and promote mitochondrial biogenesis. PGC- $1 \alpha$ and MEF2 cooperate to drive expression of GLUT4, thereby increasing glycolysis and/or glucose oxidation by augmenting glucose import, and may participate in driving expression of genes involved in hypertrophy such as contractile proteins. Increased intracellular calcium concentration and activation of calmodulin also activate the protein phosphatase calcineurin, which dephosphorylates and activates the nuclear factor of activated T cell (NFAT) transcription factor family that is involved in driving the hypertrophic program. Calcineurin may activate MEF2 directly but the mechanism of this process has not been elucidated. Numerous other signaling pathways are expected to interact with components of this model - for example, the phosphatidylinositol 3-kinase/glycogen synthase kinase-3 $\beta$ (PI-3K/GSK$3 \beta$ ) pathway - since GSK- $3 \beta$ regulates NFAT transcriptional activity. 
that activation of AMPK results in increased expression of PGC- $1 \alpha$, while a dominant-negative AMPK mutant blocked an increase in PGC- $1 \alpha$ expression in response to ATP depletion (Terada et al., 2002; Zong et al., 2002; Irrcher et al., 2003). At the same time, the expression of GLUT4, the primary insulin-sensitive glucose transporter in the heart and a direct transcriptional target of PGC- $1 \alpha$ and MEF2 (Michael et al., 2001), is increased in response to increased intracellular calcium or in response to the AMPK agonist AICAR (5-aminoimidazole-4carboxamide-1-beta-D-ribofuranoside) (Ojuka et al., 2002b). Increased GLUT4 expression may be at least partially responsible for providing the glucose necessary to drive increased glycolysis during short-term energy demands such as exercise. In the same study, it was noted that the increase in intracellular calcium or treatment with AICAR also induced expression of MEF2A and MEF2D. Together, these findings support our model in which MEF2 and PGC-1 $\alpha$ (as well as their potential downstream targets) act downstream in a pathway originating with energy status sensing by AMPK.

The activation by increased intracellular calcium is of particular note for three reasons. First, increased rate of contraction of cardiac muscle results in increased intracellular calcium concentration, likely due to decreased efficiency of calcium sequestration following the action potential or simply due to decreased time for sequestration as heart rate climbs (Braveny, 2002). Second, calcium activates the CaMKs, which have been demonstrated to drive MEF2 transcriptional activity by phosphorylating HDACs to regulate their subcellular distribution (McKinsey et al., 2000b; Zhao et al., 2001). Third, calcium also activates the protein phosphatase calcineurin, which independently drives the hypertrophic response in the heart (Molkentin et al., 1998). It also has been observed that periodic or sustained increases in intracellular calcium in muscle cells result in increased mitochondrial biogenesis (Ojuka et al., 2002a,2003). This finding is supportive of our model, since overexpression of PGC- $1 \alpha$ has been shown to be sufficient for mitochondrial biogenesis (Lehman et al., 2000). Calcium may act through MEF2 to activate expression of PGC- $1 \alpha$, resulting in the reported observation. It should be noted that cross-talk may occur between these energy- and calcium-responsive pathways, since AMPK kinase (AMPKK) can activate CaMK, while CaMKI kinase (CaMKIK) can activate AMPK through phosphorylation events, although the physiological relevance of this observation is unknown (Hawley et al., 1995).

MEF2 and PGC- $1 \alpha$ are, therefore, in an ideal position to respond to both calcium and energy depletion signals to drive the response to exercise, increasing transcription of both fatty acid oxidation enzymes and possibly contractile genes. However, it is still unclear exactly how AMPK may activate MEF2 or what all of the downstream targets of this pathway may be. It is also unclear whether there are differences in how this pathway may respond to periodic increased workload, as in exercise-induced physiologic hypertrophy, compared to sustained increased 
workload as in pathologic forms of hypertrophy. Indeed, the periodicity of stress on the heart in exercise, compared to the chronic stress of disease, may prove to be the single most-important factor in the differential responses of physiologic vs. pathologic hypertrophy. MEF2 is strongly activated during pathologic hypertrophy (Passier et al., 2000) but may be only weakly activated by exercise (H. $\mathrm{Wu}$ and $\mathrm{E}$. Olson, unpublished data). At the same time, PGC- $1 \alpha$ expression is upregulated in exercise-induced hypertrophy but is downregulated in pathologic forms of hypertrophy (Baar et al., 2002; Lehman and Kelly, 2002; Garnier et al., 2003). PGC- $1 \alpha$ expression is also upregulated in skeletal muscle following exercise (Baar et al., 2002). This disjunction between MEF2 activity and PGC- $1 \alpha$ expression suggests that there are as-yet-unidentified factors involved in this model that may modulate precise control over transcription of genes encoding contractile proteins or bioenergetic enzymes. An uncoupling of MEF2 and PGC- $1 \alpha$ pathways may be a critical feature of pathologic hypertrophy.

One possible model for disease progression is as follows: during exercise or other short-term stress, activation of AMPK and CaMK increases activity of MEF2, which then drives PGC- $1 \alpha$ expression. Together, these two factors increase transcription of the GLUT4 gene; individually, PGC- $1 \alpha$ coactivates $\operatorname{PPAR} \gamma$ to increase transcription of genes encoding enzymes involved in fatty acid oxidation, while MEF2 (possibly with the involvement of PGC- $1 \alpha$ and likely in conjunction with calcineurin activation) drives contractile gene expression. With chronic stress, an unknown factor inhibits transcription of PGC- $1 \alpha$, while MEF2 activity remains constant or may even increase, particularly if calcineurin is activated by elevated intracellular calcium. One possibility for inhibition of PGC- $1 \alpha$ expression is specific recruitment of HDACs to the PGC- $1 \alpha$ promoter. The net result is downregulation of fatty acid oxidation enzymes and GLUT4, while contractile protein expression is maintained, resulting in hypertrophy. GLUT1 levels increase to stimulate glucose import, supporting increased glycolysis and glucose oxidation and providing energy to maintain a compensated state. If the stress is prolonged sufficiently or if there are underlying genetic defects resulting in inefficient energy production or use, the heart shifts from compensation to decompensation. Elevated ROS production or myocyte dropout may accelerate this process. Fibrosis may occur as a result of physical stresses on the heart - for example, from increased wall tension, increased afterload (e.g., hypertension), or increased preload (e.g., reduced systolic ejection). Therapeutic intervention at a variety of points along this pathway may provide relief for cardiac patients, as some therapies already are proving, such as glycolysis-promoting agents, antihypertensives, and positive inotropes. As our understanding of the contributions of various pathways to the etiology of hypertrophy and heart failure improves, novel treatments will present themselves. 


\section{REFERENCES}

Abel ED, Kaulbach HC, Tian R, Hopkins JC, Duffy J, Doetschman T, Minnemann T, Boers ME, Hadro E, Oberste-Berghaus C, Quist W, Lowell BB, Ingwall JS, Kahn BB 1999 Cardiac hypertrophy with preserved contractile function after selective deletion of GLUT4 from the heart. J Clin Invest 104:1703-1714

Allard MF, Schonekess BO, Henning SL, English DR, Lopaschuk GD 1994 Contribution of oxidative metabolism and glycolysis to ATP production in hypertrophied hearts. Am J Physiol 267:H742-H750

Antonicka H, Mattman A, Carlson CG, Glerum DM, Hoffbuhr KC, Leary SC, Kennaway NG, Shoubridge EA 2003 Mutations in COX15 produce a defect in the mitochondrial heme biosynthetic pathway, causing early-onset fatal hypertrophic cardiomyopathy. Am J Hum Genet 72:101-114

Antos CL, McKinsey TA, Frey N, Kutschke W, McAnally J, Shelton JM, Richardson JA, Hill JA, Olson EN 2002 Activated glycogen synthase-3 beta suppresses cardiac hypertrophy in vivo. Proc Natl Acad Sci USA 99:907-912

Arad M, Seidman JG, Seidman CE 2002 Phenotypic diversity in hypertrophic cardiomyopathy. Hum Mol Genet 11:2499-2506

Ashrafian H, Redwood C, Blair E, Watkins H 2003 Hypertrophic cardiomyopathy: a paradigm for myocardial energy depletion. Trends Genet 19:263-268

Baar K, Wende AR, Jones TE, Marison M, Nolte LA, Chen M, Kelly DP, Holloszy JO 2002 Adaptations of skeletal muscle to exercise: rapid increase in the transcriptional coactivator PGC-1. FASEB J 16:1879-1886

Basso C, Corrado D, Thiene G 1999 Cardiovascular causes of sudden death in young individuals including athletes. Cardiol Rev 7:127-135

Black BL, Olson EN 1998 Transcriptional control of muscle development by myocyte enhancer factor-2 (MEF2) proteins. Annu Rev Cell Dev Biol 14:167-196

Braveny P 2002 Heart, calcium and time. Exp Clin Cardiol 7:1

Bueno OF, De Windt LJ, Tymitz KM, Witt SA, Kimball TR, Klevitsky R, Hewett TE, Jones SP, Lefer DJ, Peng CF, Kitsis RN, Molkentin JD 2000 The MEK1-ERK1/2 signaling pathway promotes compensated cardiac hypertrophy in transgenic mice. EMBO J 19:6341-6350

Carvajal K, Moreno-Sanchez R 2003 Heart metabolic disturbances in cardiovascular diseases. Arch Med Res 34:89-99

Coven DL, Hu X, Cong L, Bergeron R, Shulman GI, Hardie DG, Young LH 2003 Physiologic role of AMP-activated protein kinase (AMPK) in the heart: graded activation during exercise. Am J Physiol Endocrinol Metab 285:E629-E636

Czubryt MP, Panagia V, Pierce GN 1996 Role of free radicals, peroxides and oxidized lipoproteins in second messenger system dysfunction. In: Karmazyn M, ed. Myocardial Ischemia: Mechanisms, Reperfusion, Protection. Birkhauser Verlag: Basel; 57-69

Czubryt MP, McAnally J, Fishman GI, Olson EN 2003 Regulation of peroxisome proliferatoractivated receptor gamma coactivator 1 alpha (PGC-1 alpha) and mitochondrial function by MEF2 and HDAC5. Proc Natl Acad Sci USA 100:1711-1716

de las Fuentes L, Herrero P, Peterson LR, Kelly DP, Gropler RJ, Davila-Roman VG 2003 Myocardial fatty acid metabolism: independent predictor of left ventricular mass in hypertensive heart disease. Hypertension 41:83-87

De Windt LJ, Lim HW, Bueno OF, Liang Q, Delling U, Braz JC, Glascock BJ, Kimball TF, del Monte F, Hajjar RJ, Molkentin JD 2001 Targeted inhibition of calcineurin attenuates cardiac hypertrophy in vivo. Proc Natl Acad Sci USA 98:3322-3327

Eckner R, Yao TP, Oldread E, Livingston DM 1996 Interaction and functional collaboration of p300/CBP and bHLH proteins in muscle and B-cell differentiation. Genes Dev 10:2478-2490 
Eichhorn EJ, Heesch CM, Barnett JH, Alvarez LG, Fass SM, Grayburn PA, Hatfield BA, Marcoux LG, Malloy CR 1994 Effect of metoprolol on myocardial function and energetics in patients with nonischemic dilated cardiomyopathy: a randomized, double-blind, placebocontrolled study. J Am Coll Cardiol 24:1310-1320

Esposito LA, Melov S, Panov A, Cottrell BA, Wallace DC 1999 Mitochondrial disease in mouse results in increased oxidative stress. Proc Natl Acad Sci USA 96:4820-4825

Fralix TA, Heineman FW, Balaban RS 1991 Effect of work on intracellular calcium of the intact heart. Am J Physiol 261:54-59

Frey N, Olson EN 2003 Cardiac hypertrophy: the good, the bad, and the ugly. Annu Rev Physiol 65:45-79

Futterman LG, Myerburg R 1998 Sudden death in athletes: an update. Sports Med 26:335-350

Garnier A, Fortin D, Delomenie C, Momken I, Veksler V, Ventura-Clapier R 2003 Depressed mitochondrial transcription factors and oxidative capacity in rat failing cardiac and skeletal muscles. J Physiol 551:491-501

Green DR, Reed JC 1998 Mitochondria and apoptosis. Science 281:1309-1312

Handschin C, Rhee J, Lin J, Tarr PT, Spiegelman BM 2003 An autoregulatory loop controls peroxisome proliferator-activated receptor gamma coactivator 1alpha expression in muscle. Proc Natl Acad Sci USA 100:7111-7116

Hawley SA, Selbert MA, Goldstein EG, Edelman AM, Carling D, Hardie DG 1995 5'-AMP activates the AMP-activated protein kinase cascade, and $\mathrm{Ca} 2+/$ calmodulin activates the calmodulin-dependent protein kinase I cascade, via three independent mechanisms. J Biol Chem 270:27186-27191

Haykowsky MJ, Dressendorfer R, Taylor D, Mandic S, Humen D 2002 Resistance training and cardiac hypertrophy: unravelling the training effect. Sports Med 32:837-849

Hopkins TA, Dyck JR, Lopaschuk GD 2003 AMP-activated protein kinase regulation of fatty acid oxidation in the ischaemic heart. Biochem Soc Trans 31:207-212

Ide T, Tsutsui H, Kinugawa S, Suematsu N, Hayashidani S, Ichikawa K, Utsumi H, Machida Y, Egashira K, Takeshita A 2000 Direct evidence for increased hydroxyl radicals originating from superoxide in the failing myocardium. Circ Res 86:152-157

Irrcher I, Adhihetty PJ, Sheehan T, Joseph AM, Hood DA 2003 PPARgamma coactivator-1alpha expression during thyroid hormone- and contractile activity-induced mitochondrial adaptations. Am J Physiol Cell Physiol 284:C1669-C1677

Jalil JE, Doering CW, Janicki JS, Pick R, Shroff SG, Weber KT 1989 Fibrillar collagen and myocardial stiffness in the intact hypertrophied rat left ventricle. Circ Res 64:1041-1050

Jung WI, Dietze GJ 1999 31P nuclear magnetic resonance spectroscopy: a noninvasive tool to monitor metabolic abnormalities in left ventricular hypertrophy in human. Am J Cardiol $83: 19 \mathrm{H}-24 \mathrm{H}$

Kitzman DW 2000 Heart failure with normal systolic function. Clin Geriatr Med 16:489-512

Kuwahara F, Kai H, Tokuda K, Kai M, Takeshita A, Egashira K, Imaizumi T 2002 Transforming growth factor-beta function blocking prevents myocardial fibrosis and diastolic dysfunction in pressure-overloaded rats. Circulation 106:130-135

Langfort J, Viese M, Ploug T, Dela F 2003 Time course of GLUT4 and AMPK protein expression in human skeletal muscle during one month of physical training. Scand J Med Sci Sports 13:169-174

Lehman JJ, Kelly DP 2002 Transcriptional activation of energy metabolic switches in the developing and hypertrophied heart. Clin Exp Pharmacol Physiol 29:339-345

Lehman JJ, Barger PM, Kovacs A, Saffitz JE, Medeiros DM, Kelly DP 2000 Peroxisome proliferator-activated receptor gamma coactivator-1 promotes cardiac mitochondrial biogenesis. J Clin Invest 106:847-856 
Leong HS, Grist M, Parsons H, Wambolt RB, Lopaschuk GD, Brownsey R, Allard MF 2002 Accelerated rates of glycolysis in the hypertrophied heart: are they a methodological artifact? Am J Physiol Endocrinol Metab 282:E1039-E1045

Li JM, Gall NP, Grieve DJ, Chen M, Shah AM 2002 Activation of NADPH oxidase during progression of cardiac hypertrophy to failure. Hypertension 40:477-484

Liao R, Jain M, Cui L, D'Agostino J, Aiello F, Luptak I, Ngoy S, Mortensen RM, Tian R 2002 Cardiac-specific overexpression of GLUT1 prevents the development of heart failure attributable to pressure overload in mice. Circulation 106:2125-2131

Lin J, Wu H, Tarr PT, Zhang CY, Wu Z, Boss O, Michael LF, Puigserver P, Isotani E, Olson EN, Lowell BB, Bassel-Duby R, Spiegelman BM 2002 Transcriptional co-activator PGC-1 alpha drives the formation of slow-twitch muscle fibres. Nature 418:797-801

Liu J, Wang C, Murakami Y, Gong G, Ishibashi Y, Prody C, Ochiai K, Bache RJ, Godinot C, Zhang J 2001 Mitochondrial ATPase and high-energy phosphates in failing hearts. Am J Physiol Heart Circ Physiol 281:H1319-H1326

Lu J, McKinsey TA, Nicol RL, Olson EN 2000a Signal-dependent activation of the MEF2 transcription factor by dissociation from histone deacetylases. Proc Natl Acad Sci USA 97:4070-4075

Lu J, McKinsey TA, Zhang CL, Olson EN 2000b Regulation of skeletal myogenesis by association of the MEF2 transcription factor with class II histone deacetylases. Mol Cell 6:233-244

Marin-Garcia J, Goldenthal MJ 2002 Understanding the impact of mitochondrial defects in cardiovascular disease: a review. J Card Fail 8:347-361

McKinsey TA, Zhang CL, Lu J, Olson EN 2000a Signal-dependent nuclear export of a histone deacetylase regulates muscle differentiation. Nature 408:106-111

McKinsey TA, Zhang CL, Olson EN 2000b Activation of the myocyte enhancer factor-2 transcription factor by calcium/calmodulin-dependent protein kinase-stimulated binding of 14-3-3 to histone deacetylase 5. Proc Natl Acad Sci USA 97:14400-14405

Michael LF, Wu Z, Cheatham RB, Puigserver P, Adelmant G, Lehman JJ, Kelly DP, Spiegelman BM 2001 Restoration of insulin-sensitive glucose transporter (GLUT4) gene expression in muscle cells by the transcriptional coactivator PGC-1. Proc Natl Acad Sci USA 98:3820-3825

Milner DJ, Taffet GE, Wang X, Pham T, Tamura T, Hartley C, Gerdes AM, Capetanaki Y 1999 The absence of desmin leads to cardiomyocyte hypertrophy and cardiac dilation with compromised systolic function. J Mol Cell Cardiol 31:2063-2076

Milner DJ, Mavroidis M, Weisleder N, Capetanaki Y 2000 Desmin cytoskeleton linked to muscle mitochondrial distribution and respiratory function. J Cell Biol 150:1283-1298

Molkentin JD, Lu JR, Antos CL, Markham B, Richardson J, Robbins J, Grant SR, Olson EN 1998 A calcineurin-dependent transcriptional pathway for cardiac hypertrophy. Cell 93:215228

Montessuit C, Thorburn A 1999 Transcriptional activation of the glucose transporter GLUT1 in ventricular cardiac myocytes by hypertrophic agonists. J Biol Chem 274:9006-9012

Morisco C, Sadoshima J, Trimarco B, Arora R, Vatner DE, Vatner SF 2003 Is treating cardiac hypertrophy salutary or detrimental: the two faces of Janus. Am J Physiol Heart Circ Physiol 284:H1043-H1047

Naya FJ, Black BL, Wu H, Bassel-Duby R, Richardson JA, Hill JA, Olson EN 2002 Mitochondrial deficiency and cardiac sudden death in mice lacking the MEF2A transcription factor. Nature Med 8:1303-1309

Nicol RL, Frey N, Pearson G, Cobb M, Richardson J, Olson EN 2001 Activated MEK5 induces serial assembly of sarcomeres and eccentric cardiac hypertrophy. EMBO J 20:2757-2767

Oakley D 2001 General cardiology: the athlete's heart. Heart 86:722-726 
Ojuka EO, Jones TE, Han DH, Chen M, Wamhoff BR, Sturek M, Holloszy JO 2002a Intermittent increases in cytosolic $\mathrm{Ca} 2+$ stimulate mitochondrial biogenesis in muscle cells. Am J Physiol Endocrinol Metab 283:E1040-E1045

Ojuka EO, Jones TE, Nolte LA, Chen M, Wamhoff BR, Sturek M, Holloszy JO 2002b Regulation of GLUT4 biogenesis in muscle: evidence for involvement of AMPK and $\mathrm{Ca}(2+)$. Am J Physiol Endocrinol Metab 282:E1008-E1013

Ojuka EO, Jones TE, Han DH, Chen M, Holloszy JO 2003 Raising Ca2 + in L6 myotubes mimics effects of exercise on mitochondrial biogenesis in muscle. FASEB J 17:675-681

Oparil S, Bishop SP, Clubb FJ Jr 1984 Myocardial cell hypertrophy or hyperplasia. Hypertension 6:III $38-43$

Passier R, Zeng H, Frey N, Naya FJ, Nicol RL, McKinsey TA, Overbeek P, Richardson JA, Grant SR, Olson EN 2000 CaM kinase signaling induces cardiac hypertrophy and activates the MEF2 transcription factor in vivo. J Clin Invest 105:1395-1406

Prichard BN, Owens CW, Smith CC, Walden RJ 1991 Heart and catecholamines. Acta Cardiol 46:309-322

Razeghi P, Young ME, Ying J, Depre C, Uray IP, Kolesar J, Shipley GL, Moravec CS, Davies PJ, Frazier OH, Taegtmeyer H 2002 Downregulation of metabolic gene expression in failing human heart before and after mechanical unloading. Cardiology 97:203-209

Rothermel BA, McKinsey TA, Vega RB, Nicol RL, Mammen P, Yang J, Antos CL, Shelton JM, Bassel-Duby R, Olson EN, Williams RS 2001 Myocyte-enriched calcineurin-interacting protein, MCIP1, inhibits cardiac hypertrophy in vivo. Proc Natl Acad Sci USA 98:3328-3333

Sack MN, Rader TA, Park S, Bastin J, McCune SA, Kelly DP 1996 Fatty acid oxidation enzyme gene expression is downregulated in the failing heart. Circulation 94:2837-2842

Sadoshima J, Izumo S 1997 The cellular and molecular response of cardiac myocytes to mechanical stress. Annu Rev Physiol 59:551-571

Sartorelli V, Huang J, Hamamori Y, Kedes L 1997 Molecular mechanisms of myogenic coactivation by $\mathrm{p} 300$ : direct interaction with the activation domain of MyoD and with the MADS box of MEF2C. Mol Cell Biol 17:1010-1026

Sayen MR, Gustafsson AB, Sussman MA, Molkentin JD, Gottlieb RA 2003 Calcineurin transgenic mice have mitochondrial dysfunction and elevated superoxide production. Am J Physiol Cell Physiol 284:C562-C570

Scharhag J, Schneider G, Urhausen A, Rochette V, Kramann B, Kindermann W 2002 Athlete's heart: right and left ventricular mass and function in male endurance athletes and untrained individuals determined by magnetic resonance imaging. J Am Coll Cardiol 40:1856-1863

Slepak TI, Webster KA, Zang J, Prentice H, O’Dowd A, Hicks MN, Bishopric NH 2001 Control of cardiac-specific transcription by p300 through myocyte enhancer factor-2D. J Biol Chem 276:7575-7585

Terada S, Goto M, Kato M, Kawanaka K, Shimokawa T, Tabata I 2002 Effects of low-intensity prolonged exercise on PGC-1 mRNA expression in rat epitrochlearis muscle. Biochem Biophys Res Commun 296:350-354

Tian R, Musi N, D'Agostino J, Hirshman MF, Goodyear LJ 2001 Increased adenosine monophosphate-activated protein kinase activity in rat hearts with pressure-overload hypertrophy. Circulation 104:1664-1669

van den Heuvel AF, van Veldhuisen DJ, van der Wall EE, Blanksma PK, Siebelink HM, Vaalburg WM, van Gilst WH, Crijns HJ 2000 Regional myocardial blood flow reserve impairment and metabolic changes suggesting myocardial ischemia in patients with idiopathic dilated cardiomyopathy. J Am Coll Cardiol 35:19-28

van der Vusse GJ, van Bilsen M, Glatz JF 2000 Cardiac fatty acid uptake and transport in health and disease. Cardiovasc Res 45:279-293 
Vega RB, Huss JM, Kelly DP 2000 The coactivator PGC-1 cooperates with peroxisome proliferatoractivated receptor alpha in transcriptional control of nuclear genes encoding mitochondrial fatty acid oxidation enzymes. Mol Cell Biol 20:1868-1876

Wallhaus TR, Taylor M, DeGrado TR, Russell DC, Stanko P, Nickles RJ, Stone CK 2001 Myocardial free fatty acid and glucose use after carvedilol treatment in patients with congestive heart failure. Circulation 103:2441-2446

Wencker D, Chandra M, Nguyen K, Miao W, Garantziotis S, Factor SM, Shirani J, Armstrong RC, Kitsis RN 2003 A mechanistic role for cardiac myocyte apoptosis in heart failure. J Clin Invest 111:1497-1504

Yamamoto S, Yang G, Zablocki D, Liu J, Hong C, Kim SJ, Soler S, Odashima M, Thaisz J, Yehia G, Molina CA, Yatani A, Vatner DE, Vatner SF, Sadoshima J 2003 Activation of Mst1 causes dilated cardiomyopathy by stimulating apoptosis without compensatory ventricular myocyte hypertrophy. J Clin Invest 111:1463-1474

Ye Y, Gong G, Ochiai K, Liu J, Zhang J 2001 High-energy phosphate metabolism and creatine kinase in failing hearts: a new porcine model. Circulation 103:1570-1576

Young LH, Renfu Y, Russell R, Hu X, Caplan M, Ren J, Shulman GI, Sinusas AJ 1997 Low-flow ischemia leads to translocation of canine heart GLUT-4 and GLUT-1 glucose transporters to the sarcolemma in vivo. Circulation 95:415-422

Young LH, Russell RR 3rd, Yin R, Caplan MJ, Ren J, Bergeron R, Shulman GI, Sinusas AJ 1999 Regulation of myocardial glucose uptake and transport during ischemia and energetic stress. Am J Cardiol 83:25H-30H

Yu Z, Redfern CS, Fishman GI 1996 Conditional transgene expression in the heart. Circ Res 79:691-697

Zhang CL, McKinsey TA, Chang S, Antos CL, Hill JA, Olson EN 2002 Class II histone deacetylases act as signal-responsive repressors of cardiac hypertrophy. Cell 110:479-488

Zhao X, Ito A, Kane CD, Liao TS, Bolger TA, Lemrow SM, Means AR, Yao TP 2001 The modular nature of histone deacetylase HDAC4 confers phosphorylation-dependent intracellular trafficking. J Biol Chem 276:35042-35048

Zong H, Ren JM, Young LH, Pypaert M, Mu J, Birnbaum MJ, Shulman GI 2002 AMP kinase is required for mitochondrial biogenesis in skeletal muscle in response to chronic energy deprivation. Proc Natl Acad Sci USA 99:15983-15987 